\title{
A Fuzzy Data Envelopment Analysis Approach based on Parametric Programming
}

\author{
S.H. Razavi, H. Amoozad, E.K. Zavadskas, S.S. Hashemi
}

\section{Seyed Hossein Razavi Hajiagha}

Institute for Trade Studies and Research, No. 240, North Kargar St., Tehran, Iran, s.hossein.r@gmail.com

\section{Hannan Amoozad Mahdiraji}

Kashan Branch, Islamic Azad University,

Kashan, Iran,

h.amoozad@ut.ac.ir

\section{Edmundas Kazimieras Zavadskas*}

$3^{*}$ Vilnius Gediminas Technical University,

Faculty of Civil Engineering, Sauletekio al. 11,

LT-10223Vilnius, Lithuania.

edmundas.zavadskas@vgtu.lt

*Corresponding author

\section{Shide Sadat Hashemi}

Kashan Branch, Islamic Azad University,

Kashan, Iran,

shide_hashemi@yahoo.com

\begin{abstract}
In this paper, a fuzzy version of original data envelopment models, CCR and BCC, is extended and its solution approach is developed. The basic idea of the proposed method is to transform the original DEA model to an equivalent linear parametric programming model, applying the notion of $\alpha$-cuts. Then, a bi-objective model is constructed which its solution has determined the optimal range of decision making units efficiency. The proposed method can be used both for symmetric and asymmetric fuzzy numbers, while the feasibility of its solution for the original problem is guaranteed. The application of the proposed method is examined in two numerical examples and its results are compared with two current models of fuzzy DEA.

Keywords: Data envelopment analysis; Fuzzy numbers; $\alpha$-cuts; Parametric programming.
\end{abstract}

\section{Introduction}

From the early stages of modernization, the limitation of resources was one of the major challenges in managerial decisions. This limitation motivated the managers to be sensitive about the utilization of acquired resources. The origin of efficiency problem can be referred to this sensitivity. Roughly speaking, efficiency tries to answer this question: how well an organization uses its resources to produce the desired outputs? Economists suggest the concept of production function as a tool to appraise efficiency and therefore, a majority of methods that are introduced for efficiency appraisal are based on the approximation of this function (see [15] for a definition of production function). Based on the concept of production function, the efficiency evaluation methods can be classified into two groups: (1) parametric methods which directly approximate the production function, like stochastic frontier analysis [20], and (2) non-parametric methods which indirectly approximate this function. Data envelopment analysis is one of the well known and widely accepted methods in non parametric class [6]. 
Farell (1957) in his paper introduced a method of efficiency evaluation which is known as the origin of DEA. According to the Pareto-Koopmans definition, he divided the efficiency of each unit into two technical and assignment components [12]. Later, in 1978, Charnes, Cooper, and Rhodes developed the DEA method based on the Farells model. The first DEA model was called CCR model due to its authors [4]. After 1978, the DEA method was widely known and accepted as a permanent paradigm in efficiency evaluation. For instance, Emrouznejad [11] and Cook and Seiford [7] surveyed more than thousands of papers and applications of DEA in different fields. DEA is a set of linear programming based methods for evaluation the efficiency of a group of homogeneous units which use a set of inputs to produce a set of outputs. DEA considers the efficiency of each unit as the ratio between its weighted sums of outputs to the weighted sums of inputs. In contrast with the classical methods of constant weights, DEA allows each unit to take its variable weights such that its efficiency is maximized, while the efficiency of all units is constrained to be less than one. It can be concluded that the DEA weights are closely related to its inputs and outputs data, and a small swing in units data will have a great influence on the DEA results. The original DEA models were developed based on crisp and deterministic data and no deviation in data were allowed. However, in practical applications, this assumption is violated.

Scholars proposed some frameworks to deal with data uncertainty and non crispness. Some papers examined the efficiency problem under stochastic data $[27,28]$. Bellman and Zadeh [2] in their highly cited paper introduced the concept of decision making in a fuzzy environment. While many inputs and outputs are stated by qualitative or lingual variables, applications of the fuzzy sets theory in DEA are proposed in literature.

The application of fuzzy sets theory in DEA can be traced to Sengupta [29]. Since that time, there are a continuously increasing interest on fuzzy DEA methods and applications. HatamiMarbini et al. [14] classified the fuzzy DEA method into four primary categories which some instances are just introduced here: (1) the tolerance approach [29], (2) the $\alpha$-level based approach [19, 26], (3) the fuzzy ranking approach [13], and (4) the possibility approach [21,22]. Also, some approaches like Luban [23], Wang et al. [31], and Zerafat Angiz et al. [33] are known as other developments in fuzzy DEA.

In this paper, a method is proposed to solve the fuzzy DEA problems by transformation of fuzzy DEA problem to an equivalent interval problem, using the concept of $\alpha$-cuts. The obtained interval problem is a parametric problem based on $\alpha$ which a solution method is proposed to solve it as a bi-objective problem with the concept of compromise programming. The Pareto efficiency of the transformed interval problem is also proved for the fuzzy DEA problem.

The rest of paper is organized as follows. Section 2 consist a brief overview on multiplier and envelopment form of DEA CCR and BCC models. The required fuzzy set definitions and operations are overviewed in section 3. The fuzzy DEA problem and its solution procedure are described in section 4. Two numerical examples are solved in section 5 and the proposed methods solutions are compared with some of the current fuzzy DEA methods. Finally, the paper is concluded in section 6 .

\section{Data envelopment analysis}

Data Envelopment Analysis (DEA) measures the relative efficiency of a set of congruent decision making units (DMUs) that consume multiple inputs to produce multiple outputs. In fact, DEA is a multi-factor productivity analysis model for measuring the relative efficiencies of a homogenous set of DMUs. The efficiency score in the presence of multiple inputs and outputs is defined as the weighted sum of outputs to the weighted sum of inputs. Let, there are $n$ DMUs which used $m$-dimensional input vector $x_{j}=\left\lfloor x_{1 j}, \ldots, x_{m j}\right\rfloor$ to produce an $s$-dimensional 
output vector $y_{j}=\left\lfloor y_{1 j}, \ldots, y_{s j}\right\rfloor$. Then, the relative efficiency of $D M U_{0}, 0 \in\{1,2, \ldots, n\}$ will be as follows:

$$
E_{0}=\sum_{r=1}^{s} u_{r} y_{r 0} / \sum_{i=1}^{m} v_{i} x_{i 0} .
$$

The basic form of CCR model can be illustrated as follows:

$$
\begin{gathered}
\operatorname{Max} \sum_{r=1}^{s} u_{r} y_{r 0} / \sum_{i=1}^{m} v_{i} x_{i 0} \\
\sum_{r=1}^{s} u_{r} y_{r j} / \sum_{i=1}^{m} v_{i} x_{i j} \leqslant 1, j=1,2, \ldots, n \\
u_{r} \geqslant 0, r=1,2, \ldots, s \\
v_{i} \geqslant 0, i=1,2, \ldots, m
\end{gathered}
$$

The model (2) is a fractional programming which is converted to a linear programming model by Charnes " Cooper [4] variable transformation as follows:

$$
\begin{gathered}
\operatorname{Max} \sum_{r=1}^{s} u_{r} y_{r 0} \\
\sum_{i=1}^{m} v_{i} x_{i 0}=1, \\
\sum_{r=1}^{s} u_{r} y_{r j}-\sum_{i=1}^{m} v_{i} x_{i j} \leqslant 0, j=1,2, \ldots, n \\
u_{r} \geqslant 0, r=1,2, \ldots, s \\
v_{i} \geqslant 0, i=1,2, \ldots, m
\end{gathered}
$$

Model (3) is called the multiplier output oriented CCR model. The CCR models are extended under the constant return to scale assumption. In the case of variable return to scale, the BCC model [1] can be used. The BCC formulation is as follows:

$$
\begin{gathered}
\operatorname{Max} \sum_{r=1}^{s} u_{r} y_{r 0} \\
\sum_{i=1}^{m} v_{i} x_{i 0}-v_{0}=1, \\
\sum_{r=1}^{s} u_{r} y_{r j}-\sum_{i=1}^{m} v_{i} x_{i j}-v_{0} \leqslant 0, j=1,2, \ldots, n \\
u_{r} \geqslant 0, r=1,2, \ldots, s \\
v_{i} \geqslant 0, i=1,2, \ldots, m
\end{gathered}
$$

Where, is the free in sign return to scale variable. A model is CCR or BCC technically efficient if the objective functions in models (3) or (4) are equal to one and its slack variables are zero. A comprehensive review on different DEA models and their economic interpretations are discussed in $[8,25]$. 


\section{$3 \quad$ Fuzzy sets theory}

Fuzzy sets are introduced by Zadeh [32] as a generalization of classic sets. Suppose that $U$ is a universe. A fuzzy set $\tilde{A}$ in $U$ is defined as $\tilde{A}=\left\{\left(x, \mu_{\tilde{A}}(x)\right) \mid x \in U\right\}$, where $\mu_{\tilde{A}}(x)$ is called the membership function of $\tilde{A}$. If $\mu_{\tilde{A}}(x): U \rightarrow[0,1]$, then $\tilde{A}$ is called a normal fuzzy set. Jain [18] and Dubois and Prade [10] initially defined the concept of fuzzy numbers. A fuzzy number is a normal and convex fuzzy set $\tilde{A}$ in universe $U$. The most common form of fuzzy numbers in practical problems, especially in decision making related problems are trapezoidal and triangular fuzzy numbers. A trapezoidal fuzzy number can be shown as the quadruple $\tilde{A}=\left(l, m_{1}, m_{2}, r\right)$, where $l \leqslant m_{1} \leqslant m_{2} \leqslant r$ are real numbers. A trapezoidal fuzzy number $\tilde{A}$ is characterized by its membership function as follows:

$$
\mu_{\tilde{A}}(x)=\left\{\begin{array}{l}
0, x \leqslant l \\
\frac{x-l}{m_{1}-l}, \quad l \leqslant x \leqslant m_{1} \\
1, m_{1} \leqslant x \leqslant m_{2} \\
\cdot \frac{r-x}{r-m_{2}}, \quad m_{2} \leqslant x \leqslant r \\
0, x \geqslant r
\end{array}\right.
$$

Triangular fuzzy number is a specific form of trapezoidal fuzzy numbers where $m_{1}=m_{2}$. A required concept of fuzzy numbers in this paper is the concept of $\alpha$-cuts. For a fuzzy set $\tilde{A}$, its $\alpha$ - cut is defined as $\tilde{A}=\left\{x \in U \mid \mu_{\tilde{A}}(x) \geqslant \alpha\right\}$. The $\alpha$ - cuts can be shown as crisp intervals which are called $\alpha$ - level interval:

$$
(\tilde{A})_{\alpha}=\left[(\tilde{A})_{\alpha}^{l},(\tilde{A})_{\alpha}^{u}\right]=\left[\begin{array}{c}
\min _{x}\left\{x \in U \mid \mu_{\tilde{A}}(x) \geqslant \alpha\right\}, \\
\max _{x}\left\{x \in U \mid \mu_{\tilde{A}}(x) \geqslant \alpha\right\}
\end{array}\right]
$$

For a trapezoidal fuzzy number $\tilde{A}=\left(l, m_{1}, m_{2}, r\right)$, its $\alpha$ - level interval is determined as follows:

$$
(\tilde{A})_{\alpha}=\left[m_{1} \alpha+l(1-\alpha), m_{2} \alpha+r(1-\alpha)\right]
$$

The arithmetic operations can be defined on fuzzy numbers [34]. An alternative way of fuzzy arithmetic can be defined based on interval arithmetic of $\alpha$-level intervals. The interval arithmetic is described in Moore et al. [24]. If $\tilde{A}$ and $\tilde{B}$ be two fuzzy numbers with $\alpha$-level intervals $(\tilde{A})_{\alpha}=\left\lfloor(\tilde{A})_{\alpha}^{l},(\tilde{A})_{\alpha}^{u}\right\rfloor$ and $(\tilde{B})_{\alpha}=\left\lfloor(\tilde{B})_{\alpha}^{l},(\tilde{B})_{\alpha}^{u}\right\rfloor$, then it follows that $[3,30]$ :

$$
\begin{gathered}
(\tilde{A})_{\alpha}+(\tilde{B})_{\alpha}=\left\lfloor(\tilde{A})_{\alpha}^{l}+(\tilde{B})_{\alpha}^{l},(\tilde{A})_{\alpha}^{u}+(\tilde{B})_{\alpha}^{u}\right\rfloor \\
(\tilde{A})_{\alpha}-(\tilde{B})_{\alpha}=\left\lfloor(\tilde{A})_{\alpha}^{l}-(\tilde{B})_{\alpha}^{u},(\tilde{A})_{\alpha}^{u}-(\tilde{B})_{\alpha}^{l}\right\rfloor \\
(\tilde{A})_{\alpha}(\tilde{B})_{\alpha}=\left[\begin{array}{l}
\min \left\{(\tilde{A})_{\alpha}^{l}(\tilde{B})_{\alpha}^{l},(\tilde{A})_{\alpha}^{l}(\tilde{B})_{\alpha}^{u},(\tilde{A})_{\alpha}^{u}(\tilde{B})_{\alpha}^{l},(\tilde{A})_{\alpha}^{u}(\tilde{B})_{\alpha}^{u},\right\}, \\
\max \left\{(\tilde{A})_{\alpha}^{l}(\tilde{B})_{\alpha}^{l},(\tilde{A})_{\alpha}^{l}(\tilde{B})_{\alpha}^{u},(\tilde{A})_{\alpha}^{u}(\tilde{B})_{\alpha}^{l},(\tilde{A})_{\alpha}^{u}(\tilde{B})_{\alpha}^{u},\right\}
\end{array}\right]
\end{gathered}
$$




$$
\begin{aligned}
& 1 /(\tilde{B})_{\alpha}=\left\lfloor 1 /(\tilde{B})_{\alpha}^{l}, 1 /(\tilde{B})_{\alpha}^{u}\right\rfloor \\
& (\tilde{A})_{\alpha} \div(\tilde{B})_{\alpha}=(\tilde{A})_{\alpha} \times \frac{1}{(\tilde{B})_{\alpha}}
\end{aligned}
$$

For an interval number $(\tilde{A})_{\alpha}=\left\lfloor(\tilde{A})_{\alpha}^{l},(\tilde{A})_{\alpha}^{u}\right\rfloor$, its center is defined as follows:

$$
\left[(\tilde{A})_{\alpha}\right]_{c}=\frac{(\tilde{A})_{\alpha}^{l}+(\tilde{A})_{\alpha}^{u}}{2}
$$

\section{Fuzzy Data Envelopment Analysis}

A fuzzy DEA problem can be stated as follows: consider a group of $n$ decision making units. Each $D M U_{j}, j=1,2, \ldots, n$ used a set of fuzzy inputs $\tilde{X}_{i}=\left(\tilde{x}_{i 1}, \tilde{x}_{i 2}, \ldots, \tilde{x}_{i m}\right)$ to produce a set of fuzzy outputs $\tilde{Y}_{i}=\left(\tilde{y}_{i 1}, \tilde{y}_{i 2}, \ldots, \tilde{y}_{i s}\right)$, where components of $\tilde{X}_{i}$ and $\tilde{Y}_{i}$ are fuzzy numbers. Then, the fuzzy CCR model can be formulated as follows:

$$
\begin{gathered}
\operatorname{Max} \sum_{r=1}^{s} u_{r} \tilde{y}_{r 0} \\
\sum_{i=1}^{m} v_{i} \tilde{x}_{i 0} \cong 1 \\
\sum_{r=1}^{s} u_{r} \tilde{y}_{r j}-\sum_{i=1}^{m} v_{i} \tilde{x}_{i j} \tilde{\leqslant} 0, j=1,2, \ldots, n \\
u_{r} \geqslant 0, r=1,2, \ldots, s \\
v_{i} \geqslant 0, i=1,2, \ldots, m
\end{gathered}
$$

Where $\cong$ and $\tilde{\xi}$ are fuzzy equality and inequality, means "approximately equal to" and "approximately smaller than". The model in Eq. (14) is an input oriented fuzzy CCR model (I F-CCR). In a specific $\alpha$-level, $\alpha \in[0,1]$, the $\alpha$-level efficiency of $D M U_{0}, E_{\alpha}$, can be achieved by solving the following model:

$$
\begin{gathered}
E_{\alpha}=\operatorname{Max} \sum_{r=1}^{s} u_{r}\left(\tilde{y}_{r 0}\right)_{\alpha} \\
\sum_{i=1}^{m} v_{i}\left(\tilde{x}_{i 0}\right)_{\alpha}=1 \\
\sum_{r=1}^{s} u_{r}\left(\tilde{y}_{r j}\right)_{\alpha}-\sum_{i=1}^{m} v_{i}\left(\tilde{x}_{i j}\right)_{\alpha} \leqslant 0, j=1,2, \ldots, n \\
u_{r} \geqslant 0, r=1,2, \ldots, s \\
v_{i} \geqslant 0, i=1,2, \ldots, m
\end{gathered}
$$


While $\left(\tilde{y}_{r j}\right)_{\alpha} \subseteq \tilde{y}_{r j}$ and $\left(\tilde{x}_{i 0}\right)_{\alpha} \subseteq \tilde{x}_{i 0}$, then for each $\alpha \in[0,1]$ the feasible space of model (15) is a subset of feasible space of model (14) and therefore, each feasible solution of (15) is a feasible solution of (14). Therefore, it can be stated that:

Lemma1. If $S_{a}$ is the feasible space of model (15) and $S_{0}$ is the feasible space of model (14), then $\forall \alpha \in[0,1], S_{\alpha} \subseteq S_{0}$.

Substituting the $\alpha$-level intervals in model (15), the model (16) will be obtained as follows:

$$
\begin{gathered}
E_{\alpha}=\operatorname{Max} \sum_{r=1}^{s} u_{r}\left[\left(\tilde{y}_{r 0}\right)_{\alpha}^{l},\left(\tilde{y}_{r 0}\right)_{\alpha}^{u}\right] \\
\sum_{i=1}^{m} v_{i}\left[\left(\tilde{x}_{i 0}\right)_{\alpha}^{l},\left(\tilde{x}_{i 0}\right)_{\alpha}^{u}\right]=1 \\
\sum_{r=1}^{s} u_{r}\left[\left(\tilde{y}_{r j}\right)_{\alpha}^{l},\left(\tilde{y}_{r j}\right)_{\alpha}^{u}\right]-\sum_{i=1}^{m} v_{i}\left[\left(\tilde{x}_{i j}\right)_{\alpha}^{l},\left(\tilde{x}_{i j}\right)_{\alpha}^{u}\right] \leqslant 0, j=1,2, \ldots, n \\
u_{r} \geqslant 0, r=1,2, \ldots, s \\
v_{i} \geqslant 0, i=1,2, \ldots, m
\end{gathered}
$$

The model (16) is an interval linear programming model and can be solved by interval linear programming techniques. To solve the model (16), first let define some ordering relations between interval numbers. The objective function of model (17) is as the following form:

$$
E_{\alpha}=\operatorname{Max}\left[\sum_{r=1}^{s} u_{r}\left(\tilde{y}_{r 0}\right)_{\alpha}^{l}, \sum_{r=1}^{s} u_{r}\left(\tilde{y}_{r 0}\right)_{\alpha}^{u}\right]
$$

According to Ishibuichi and Tanaka [17] and Das et al. [9], the $E_{\alpha}$ will be maximized if and only if its lower bound and center are maximized, i.e.:

$$
E_{\alpha}=\operatorname{Max}\left[\begin{array}{l}
\sum_{r=1}^{s} u_{r}\left(\tilde{y}_{r 0}\right)_{\alpha}^{l}, \\
\sum_{r=1}^{s} u_{r}\left(\left(\tilde{y}_{r 0}\right)_{\alpha}^{l}+\left(\tilde{y}_{r 0}\right)_{\alpha}^{u} / 2\right)
\end{array}\right]
$$

The first constraint of model (16) is justified as follows:

$$
\sum_{i=1}^{m} v_{i}\left[\frac{\left(\tilde{x}_{i 0}\right)_{\alpha}^{l}+\left(\tilde{x}_{i 0}\right)_{\alpha}^{u}}{2}\right]=1
$$

Because this constraint required that $\sum_{i=1}^{m} v_{i}\left(\tilde{x}_{i 0}\right)_{\alpha}^{l}=1$, and $\sum_{i=1}^{m} v_{i}\left(\tilde{x}_{i 0}\right)_{\alpha}^{u}=1$. Adding these equations and dividing by 2 , the Eq. (19) is obtained.

Also, the second set of constraints is modified as follows to a linear set of constraints:

$$
\left[\begin{array}{c}
\sum_{r=1}^{s} u_{r}\left(\tilde{y}_{r j}\right)_{\alpha}^{l}-\sum_{i=1}^{m} v_{i}\left(\tilde{x}_{i j}\right)_{\alpha}^{u}, \\
\sum_{r=1}^{s} u_{r}\left(\tilde{y}_{r j}\right)_{\alpha}^{u}-\sum_{i=1}^{m} v_{i}\left(\tilde{x}_{i j}\right)_{\alpha}^{l}
\end{array}\right] \leqslant 0, j=1,2, \ldots, n
$$


The constraints of the form Eq. (20) are handled as follows:

$$
\begin{gathered}
\sum_{r=1}^{s} u_{r}\left(\tilde{y}_{r j}\right)_{\alpha}^{u}-\sum_{i=1}^{m} v_{i}\left(\tilde{x}_{i j}\right)_{\alpha}^{l} \leqslant 0, j=1,2, \ldots, n \\
\sum_{r=1}^{s} u_{r}\left(\frac{\left(\tilde{y}_{r j}\right)_{\alpha}^{l}+\left(\tilde{y}_{r j}\right)_{\alpha}^{u}}{2}\right)-\sum_{i=1}^{m} v_{i}\left(\frac{\left(\tilde{x}_{i j}\right)_{\alpha}^{l}+\left(\tilde{x}_{i j}\right)_{\alpha}^{u}}{2}\right) \leqslant 0, j=1,2, \ldots, n
\end{gathered}
$$

Integrating the Eqs. (18) - (21), the following multi objective model is constructed as an equivalent model for input oriented fuzzy CCR model (14).

$$
\begin{gathered}
E_{\alpha}=\operatorname{Max} \sum_{r=1}^{s} u_{r}\left(\tilde{y}_{r 0}\right)_{\alpha}^{l} \\
\operatorname{Max} \sum_{r=1}^{s} u_{r}\left(\left(\tilde{y}_{r 0}\right)_{\alpha}^{l}+\left(\tilde{y}_{r 0}\right)_{\alpha}^{u} / 2\right) \\
\text { Subject to } \\
\sum_{i=1}^{m} v_{i}\left[\frac{\left(\tilde{x}_{i 0}\right)_{\alpha}^{l}+\left(\tilde{x}_{i 0}\right)_{\alpha}^{u}}{2}\right]=1 \\
\sum_{r=1}^{s} u_{r}\left(\tilde{y}_{r j}\right)_{\alpha}^{u}-\sum_{i=1}^{m} v_{i}\left(\tilde{x}_{i j}\right)_{\alpha}^{l} \leqslant 0, j=1,2, \ldots, n \\
u_{r=1}^{s} \tilde{y}_{r j}^{l}+\left(\tilde{y}_{r j}\right)_{\alpha}^{u} \\
u_{r} \geqslant 0, r=1,2, \ldots, s \\
v_{i} \geqslant 0, i=1,2, \ldots, m
\end{gathered}
$$

The Eq. (22) is a bi-objective parametric model. This model is then decomposed to two distinct model to (1) maximize the $E_{\alpha}^{l}$, and (2) maximize the $E_{\alpha}^{c}$. If PPS is the feasible space of model (22), these two models are formulated as follows:

$$
\begin{gathered}
\operatorname{Max}_{\alpha}^{l}=\sum_{r=1}^{s} u_{r}\left(\tilde{y}_{r 0}\right)_{\alpha}^{l} \quad(u, v) \in P P S \\
\operatorname{MinE}_{\alpha}^{c}=\sum_{r=1}^{s} u_{r}\left(\left(\tilde{y}_{r 0}\right)_{\alpha}^{l}+\left(\tilde{y}_{r 0}\right)_{\alpha}^{u} / 2\right) \quad(u, v) \in P P S
\end{gathered}
$$

The models (22) and (23) are linear programming problems which can be solved easily by available packages. The solutions of these models determine the optimal range of DMUs efficiency, i.e. $\left[E_{\alpha}^{l *}, E_{\alpha}^{U *}\right]$, which in turn is the efficiency $\alpha$-cut. In fact, while the outputs of the DMUs are determined by fuzzy numbers, their efficiency scores will be also fuzzy numbers with unknown membership function. The result of model (22) for a specific value of $\alpha$ is the efficiency membership function's $\alpha$-cut. 
The following lemma shows an important relation between models (21) and (14).

Lemma2. If $(u, v)$ is a feasible solution of model (21), it will be a feasible solution of the original fuzzy DEA model (14).

The proof is easily obtained from lemma1.

In the case of variable return to scale, the fuzzy BCC model can be formulated as follows:

$$
\begin{gathered}
E_{\alpha}=\operatorname{Max} \sum_{r=1}^{s} u_{r}\left(\tilde{y}_{r 0}\right)_{\alpha}^{l} \\
\operatorname{Max} \sum_{r=1}^{s} u_{r}\left(\left(\tilde{y}_{r 0}\right)_{\alpha}^{l}+\left(\tilde{y}_{r 0}\right)_{\alpha}^{u} / 2\right) \\
\text { Subject to } \\
\sum_{i=1}^{m} v_{i}\left[\frac{\left(\tilde{x}_{i 0}\right)_{\alpha}^{l}+\left(\tilde{x}_{i 0}\right)_{\alpha}^{u}}{2}\right]-v_{0}=1 \\
\sum_{r=1}^{s} u_{r}\left(\tilde{y}_{r j}\right)_{\alpha}^{u}-\sum_{i=1}^{m} v_{i}\left(\tilde{x}_{i j}\right)_{\alpha}^{l}-v_{0} \leqslant 0, j=1,2, \ldots, n \\
u_{r=1}\left(\frac{\left(\tilde{y}_{r j}\right)_{\alpha}^{l}+\left(\tilde{y}_{r j}\right)_{\alpha}^{u}}{2}\right)-\sum_{i=1}^{m} v_{i}\left(\frac{\left(\tilde{x}_{i j}\right)_{\alpha}^{l}+\left(\tilde{x}_{i j}\right)_{\alpha}^{u}}{2}\right)-v_{0} \leqslant 0, j=1,2, \ldots, n \\
u_{r} \geqslant 0, r=1,2, \ldots, s \\
v_{i} \geqslant 0, i=1,2, \ldots, m \\
v_{0}: \text { unrestricted }
\end{gathered}
$$

The model (24) can be solved with a similar approach to model (21). Analyzing the efficiency of DMUs with the proposed method, for a set of $n$ different values of $\alpha$, e.g. $\alpha_{i}, i=1,2, \ldots, n$ results in a set of efficiency $\alpha$-cuts $\left[E_{\alpha_{i}}^{L *}, E_{\alpha_{i}}^{U *}\right]$. Therefore, it will be necessary to obtain an integrated efficiency score for DMUs to rank them. While the membership functions of efficiency are not determined, the conventional methods of fuzzy numbers aggregation which need membership functions cannot be used. Here, the Chen and Klein [5] method is proposed to rank the efficiency scores of DMUs based on their $\alpha$-cuts, like Kao and Liu [19]. Chen and Klein [5] introduced the following index for fuzzy numbers:

$$
I_{j}=\frac{\sum_{i=0}^{n}\left(\left(E_{\alpha_{i}}^{U *}\right)-c\right)}{\sum_{i=0}^{n}\left(\left(E_{\alpha_{i}}^{U *}\right)-c\right)-\sum_{i=0}^{n}\left(\left(E_{\alpha_{i}}^{L *}\right)-d\right)}, n \rightarrow \infty
$$

Where, $c=\min _{i, j}\left\{\left(E_{\alpha_{i}}^{L *}\right)\right\}$ and $d=\max _{i, j}\left\{\left(E_{\alpha_{i}}^{U *}\right)\right\}$. While $n$ is grown, the methods validity is increased, however Chen and Klein believed that $n=3$ or 4 is sufficient. 


\section{$5 \quad$ Numerical examples}

In this section, two numerical examples are solved by the proposed method and the results are compared with previously presented methods.

Example1. Consider 4 DMUs with inputs and outputs which are presented in table1.

Table 1: Inputs and outputs of 4 DMUs

\begin{tabular}{|c|c|c|c|c|}
\hline DMU & Input & $\alpha$-cut & Output & $\alpha$-cut \\
\hline A & $(11,12,14)$ & {$[11+\alpha, 14-2 \alpha]$} & 10 & {$[10,10]$} \\
\hline B & 30 & {$[30,40]$} & $(12,13,14,16)$ & {$[12+\alpha, 16-2 \alpha]$} \\
\hline C & 40 & {$[40,40]$} & 11 & {$[11,11]$} \\
\hline D & $(45,47,52,55)$ & {$[45+2 \alpha, 55-3 \alpha]$} & $(12,15,19,22)$ & {$[12+3 \alpha, 22-3 \alpha]$} \\
\hline
\end{tabular}

Kao and Liu [19] solved this problem in an 11 point scale for $\alpha$ based on BCC model. Table 2 shows the Kao and Liu's results.

Considering the DMU D, the model (22) is designed for this DMU as follows. First, two single objective models are solved:

$E_{l}^{\alpha}(D): \operatorname{Max}(12+3 \alpha) u_{1}$

Subject to

$\left(\frac{100-\alpha}{2}\right) v_{1}+v_{0}=1$

$10 u_{1}-(11+\alpha) v_{1}-v_{0} \leqslant 0$

$(16-2 \alpha) u_{1}-30 v_{1}-v_{0} \leqslant 0$

$11 u_{1}-40 v_{1} \leqslant 0$

$(22-3 \alpha) u_{1}-(45+3 \alpha) v_{1}-v_{0} \leqslant 0$

$10 u_{1}-\left(\frac{25-\alpha}{2}\right) v_{1}-v_{0} \leqslant 0$

$\left(\frac{28-\alpha}{2}\right) u_{1}-30 v_{1}-v_{0} \leqslant 0$

$\frac{17 u_{1}}{2}-\left(\frac{100-\alpha}{2}\right) v_{1}-v_{0} \leqslant 0$

$u_{1} \geqslant 0, v_{1} \geqslant 0, v_{0}:$ unrestricted

$E_{l}^{\alpha}(D): \operatorname{Max} \frac{17}{2} u_{1}$

Subject to

$\left(\frac{100-\alpha}{2}\right) v_{1}+v_{0}=1$

$10 u_{1}-(11+\alpha) v_{1}-v_{0} \leqslant 0$

$(16-2 \alpha) u_{1}-30 v_{1}-v_{0} \leqslant 0$

$11 u_{1}-40 v_{1}-v_{0} \leqslant 0$

$(22-3 \alpha) u_{1}-(45+3 \alpha) v_{1}-v_{0} \leqslant 0$

$10 u_{1}-\left(\frac{25-\alpha}{2}\right) v_{1}-v_{0} \leqslant 0$

$\left(\frac{28-\alpha}{2}\right) u_{1}-30 v_{1}-v_{0} \leqslant 0$ 


$$
\begin{aligned}
& \frac{17 u_{1}}{2}-\left(\frac{100-\alpha}{2}\right) v_{1}-v_{0} \leqslant 0 \\
& u_{1} \geqslant 0, v_{1} \geqslant 0, v_{0}: \text { unrestrict end }
\end{aligned}
$$

\section{2.}

These models are designed and solved for different $\alpha$-levels. The results are shown in table

Let consider two sets of solutions with more details. Considering the DMUs $A$ and $C$, which their outputs are stated by crisp numbers, it is intuitionally more acceptable that their efficiency in an input oriented model and in each specific level of $\alpha$ be a crisp number, as it is in table 2 .

Now consider the DMU $A$. Solving its lower bound model with Kao and Liu [19], for $\alpha=0$, the optimal solution is as follows:

Table 2: The $\alpha$-cuts of the efficiency at eleven $\alpha$-values based on the proposed method and Kao and Liu [19] method

\begin{tabular}{|c|c|c|c|c|c|c|c|c|}
\hline $\mathrm{A}$ & \multicolumn{2}{|c|}{$\left[\left(E_{A}\right)_{\alpha}^{l},\left(E_{A}\right)_{\alpha}^{u}\right]$} & \multicolumn{2}{|c|}{$\left[\left(E_{B}\right)_{\alpha}^{l},\left(E_{B}\right)_{\alpha}^{u}\right]$} & \multicolumn{2}{|c|}{$\left[\left(E_{C}\right)_{\alpha}^{l},\left(E_{C}\right)_{\alpha}^{u}\right]$} & \multicolumn{2}{|c|}{$\left[\left(E_{D}\right)_{\alpha}^{l},\left(E_{D}\right)_{\alpha}^{u}\right]$} \\
\hline & Proposed & Kao and Liu & Proposed & Kao and Liu & Proposed & Kao and Liu & Proposed & Kao and Liu \\
\hline 0.0 & 0.9497 & {$[1.0,1.0]$} & {$[0.71,0.95]$} & {$[0.71,1.0]$} & 0.5436 & {$[0.54,0.91]$} & {$[0.54,1]$} & {$[0.74,1.0]$} \\
\hline 0.1 & 0.9557 & {$[1.0,1.0]$} & {$[0.73,0.95]$} & {$[0.73,1.0]$} & 0.5523 & {$[0.55,0.90]$} & {$[0.56,1]$} & {$[0.77,1.0]$} \\
\hline 0.2 & 0.9615 & {$[1.0,1.0]$} & {$[0.75,0.95]$} & {$[0.75,1.0]$} & 0.5612 & {$[0.56,0.88]$} & {$[0.58,1]$} & {$[0.80,1.0]$} \\
\hline 0.3 & 0.9671 & {$[1.0,1.0]$} & {$[0.76,0.95]$} & {$[0.76,1.0]$} & 0.5703 & {$[0.57,0.87]$} & {$[0.61,1]$} & {$[0.83,1.0]$} \\
\hline 0.4 & 0.9725 & {$[1.0,1.0]$} & {$[0.78,0.95]$} & {$[0.78,1.0]$} & 0.5795 & {$[0.58,0.86]$} & {$[0.63,1]$} & {$[0.86,1.0]$} \\
\hline 0.5 & 0.9776 & {$[1.0,1.0]$} & {$[0.79,0.95]$} & {$[0.79,1.0]$} & 0.5890 & {$[0.58,0.85]$} & {$[0.65,1]$} & {$[0.89,1.0]$} \\
\hline 0.6 & 0.9826 & {$[1.0,1.0]$} & {$[0.81,0.95]$} & {$[0.81,1.0]$} & 0.5987 & {$[0.59,0.83]$} & {$[0.68,1]$} & {$[0.93,1.0]$} \\
\hline 0.7 & 0.9873 & {$[1.0,1.0]$} & {$[0.83,0.95]$} & {$[0.83,1.0]$} & 0.6086 & {$[0.60,0.82]$} & {$[0.70,1]$} & {$[0.96,1.0]$} \\
\hline 0.8 & 0.9917 & {$[1.0,1.0]$} & {$[0.85,0.95]$} & {$[0.85,1.0]$} & 0.6187 & {$[0.61,0.81]$} & {$[0.73,1]$} & {$[0.99,1.0]$} \\
\hline 0.9 & 0.9960 & {$[1.0,1.0]$} & {$[0.87,0.95]$} & {$[0.87,1.0]$} & 0.6290 & {$[0.62,0.80]$} & {$[0.76,1]$} & {$[1.0,1.0]$} \\
\hline 1.0 & 1.0 & {$[1.0,1.0]$} & {$[0.88,0.95]$} & {$[0.88,1.0]$} & 0.6395 & {$[0.63,0.79]$} & {$[0.78,1]$} & {$[1.0,1.0]$} \\
\hline
\end{tabular}

$\left\lfloor u_{1}^{*}=0.1, v_{1}^{*}=0.07142857, v_{0}^{*}=0.511766\right\rfloor$. Replacing this solution in the first constraint of model (14), the following equality is obtained: $(1.29747587,1.3689044,1.51176158)=1$. However, it is clear that $1 \in(1.29747587,1.3689044,1.51176158)$ and therefore this constraint is violated. In fact, the Kao and Liu [19] method overestimated the DMUs efficiency. In this case, the proposed methods solution is:

$\left\lfloor u_{1}^{*}=0.09497207, v_{1}^{*}=0.03351955, v_{0}^{*}=0.5810056\right\rfloor$, and the considered constraint is as follows: $(0.94972065,0.9832402,1.0502793)=1$ which it is clear that $1 \in(0.94972065,0.9832402,1.0502793)$.

Example2. Saati-Mohtadi et al. [26] applied their model on an example with 10 DMUs which used two inputs in order to produce two outputs. Data are presented in table 3.

Table 4 presents the results of efficiency appraisal of DMUs based on the proposed method and Saati-Mohtadi et al. [26] method.

Applying Eq. (25) the following results are obtained:

$I_{1}=0.9407, I_{2}=0.9599, I_{3}=0.3704$,

$I_{4}=0.4629, I_{5}=0.5015, I_{6}=0.2942, I_{7}=0.1409, I_{8}=0.1439, I_{9}=0.0471, I_{1} 0=0.9243$.

Therefore, the DMUs are ranked based on their efficiencies as follows: $\tilde{E}_{2} \succ \tilde{E}_{4} \succ \tilde{E}_{10} \succ \tilde{E}_{5}$ $\succ \tilde{E}_{4} \succ \tilde{E}_{3} \succ \tilde{E}_{6} \succ \tilde{E}_{8} \succ \tilde{E}_{7} \succ \tilde{E}_{9}$ 
Table 3: Data for 10 DMUs

\begin{tabular}{ccccc}
\hline DMUs & $I_{1}$ & $I_{2}$ & $O_{1}$ & $O_{2}$ \\
\hline$D_{1}$ & $(6.0,7.0,8.0)$ & $(29.0,30.0,32.0)$ & $(35.5,38.0,41.0)$ & $(409.0,411.0,416.0)$ \\
$D_{2}$ & $(5.5,6.0,6.5)$ & $(33.0,35.0,36.5)$ & $(39.0,40.0,43.0)$ & $(478.0,480.0,484.0)$ \\
$D_{3}$ & $(7.5,9.0,10.5)$ & $(43.0,45.0,48.0)$ & $(32.0,35.0,38.0)$ & $(297.0,299.0,301.0)$ \\
$D_{4}$ & $(7.0,8.0,10.0)$ & $(37.5,39.0,42.0)$ & $(28.0,31.0,31.0)$ & $(347.0,352.0,360.0)$ \\
$D_{5}$ & $(9.0,11.0,12.0)$ & $(43.0,44.0,45.0)$ & $(33.0,35.0,38.0)$ & $(406.0,411.0,415.5)$ \\
$D_{6}$ & $(10.0,10.0,14.0)$ & $(53.0,55.0,57.5)$ & $(36.0,38.0,40.0)$ & $(282.0,286.0,289.0)$ \\
$D_{7}$ & $(10.0,12.0,14.0)$ & $(107.0,110.0,113.0)$ & $(34.5,36.0,38.0)$ & $(396.0,400.0,405.0)$ \\
$D_{8}$ & $(9.0,13.0,16.0)$ & $(95.0,100.0,101.0)$ & $(37.0,41.0,46.0)$ & $(387.0,393.0,402.0)$ \\
$D_{9}$ & $(12.0,14.0,15.0)$ & $(120.0,125.0,131.0)$ & $(24.0,27.0,28.0)$ & $(400.0,404.0,406.0)$ \\
$D_{10}$ & $(5.0,8.0,10.0)$ & $(35.0,38.0,39.0)$ & $(48.0,50.0,51.0)$ & $(470.0,470.0,470.0)$ \\
\hline \multicolumn{5}{c}{}
\end{tabular}

Table 4: DMUs efficiency scores in six $\alpha$-values based on the proposed method (P.) and SaatiMohtadi et al. [26]

\begin{tabular}{|c|c|c|c|c|c|c|c|c|}
\hline DMUs & \multicolumn{2}{|c|}{0.0} & \multicolumn{2}{|c|}{0.2} & \multicolumn{2}{|c|}{0.4} & \multicolumn{2}{|c|}{0.6} \\
\hline & $\mathrm{P}$ & Saati et al. & $\mathrm{P}$ & Saati et al. & $\mathrm{P}$ & Saati et al. & $\mathrm{P}$ & Saati et al. \\
\hline$D_{1}$ & {$[0.91,0.94]$} & 1.00 & {$[0.93,0.96]$} & 1.00 & {$[0.95,0.97]$} & 1.00 & {$[0.96,0.98]$} & 1.00 \\
\hline$D_{2}$ & {$[0.94,0.95]$} & 1.00 & {$[0.95,0.96]$} & 1.00 & {$[0.96,0.97]$} & 1.00 & {$[0.97,0.98]$} & 1.00 \\
\hline$D_{3}$ & {$[0.48,0.57]$} & 0.84 & {$[0.50,0.57]$} & 0.79 & {$[0.52,0.58]$} & 0.75 & {$[0.54,0.58]$} & 0.71 \\
\hline$D_{4}$ & {$[0.60,0.62]$} & 0.76 & {$[0.61,0.63]$} & 0.74 & {$[0.62,0.63]$} & 0.71 & {$[0.63,0.64]$} & 0.70 \\
\hline$D_{5}$ & {$[0.62,0.64]$} & 0.78 & {$[0.63,0.65]$} & 0.75 & {$[0.64,0.65]$} & 0.73 & {$[0.66,0.66]$} & 0.71 \\
\hline$D_{6}$ & {$[0.44,0.49]$} & 0.69 & {$[0.46,0.50]$} & 0.67 & {$[0.47,0.50]$} & 0.65 & {$[0.49,0.51]$} & 0.63 \\
\hline$D_{7}$ & {$[0.35,0.35]$} & 0.63 & {$[0.38,0.39]$} & 0.59 & {$[0.39,0.40]$} & 0.55 & {$[0.41,0.42]$} & 0.51 \\
\hline$D_{8}$ & {$[0.32,0.33]$} & 0.85 & {$[0.36,0.37]$} & 0.75 & {$[0.38,0.40]$} & 0.66 & {$[0.41,0.4]$} & 0.59 \\
\hline$D_{9}$ & {$[0.31,0.31]$} & 0.46 & {$[0.34,0.34]$} & 0.44 & {$[0.34,0.34]$} & 0.42 & {$[0.35,0.35]$} & 0.40 \\
\hline$D_{10}$ & {$[0.89,0.93]$} & 1.00 & {$[0.91,0.94]$} & 1.00 & {$[0.93,0.96]$} & 1.00 & {$[0.95,0.97]$} & 1.00 \\
\hline
\end{tabular}

\begin{tabular}{|c|c|c|c|c|}
\hline DMUs & \multicolumn{2}{|c|}{0.8} & \multicolumn{2}{c|}{1.0} \\
\hline & $\mathrm{P}$ & Saati et al. & $\mathrm{P}$ & Saati et al. \\
\hline$D_{1}$ & {$[0.98,0.99]$} & 1.00 & {$[1.0,1.0]$} & 1.00 \\
\hline$D_{2}$ & {$[0.98,0.99]$} & 1.00 & {$[1.0,1.0]$} & 1.00 \\
\hline$D_{3}$ & {$[0.56,0.58]$} & 0.66 & {$[0.61,0.61]$} & 0.61 \\
\hline$D_{4}$ & {$[0.64,0.65]$} & 0.68 & {$[0.65,0.65]$} & 0.66 \\
\hline$D_{5}$ & {$[0.67,0.67]$} & 0.69 & {$[0.68,0.68]$} & 0.68 \\
\hline$D_{6}$ & {$[0.53,0.54]$} & 0.60 & {$[0.58,0.58]$} & 0.58 \\
\hline$D_{7}$ & {$[0.43,0.44]$} & 0.48 & {$[0.45,0.45]$} & 0.45 \\
\hline$D_{8}$ & {$[0.45,0.46]$} & 0.53 & {$[0.47,0.47]$} & 0.47 \\
\hline$D_{9}$ & {$[0.35,0.35]$} & 0.38 & {$[0.36,0.36]$} & 0.36 \\
\hline$D_{10}$ & {$[0.97,0.98]$} & 1.00 & {$[1.0,1.0]$} & 1.00 \\
\hline
\end{tabular}


Now, let compare the results of the proposed method with [26]. Table5 presents that $D_{1}$ attain to full efficiency in all $\alpha$-levels. Suppose that $\alpha=0$. If the problem is solved with Saati-Mohtadi et al. [26] method, its results will be $u_{1}^{*}=0.02439024, u_{2}^{*}=0, v_{1}^{*}=0.1406398, v_{2}^{*}=0.005384859$. Replacing this solution in the first constraint of model (14), the result will be as follows: (1, $1.146024,1.297434)$ which the membership degree of 1 is zero and it violates the " $\cong$ relation. However, when the model is solved with the proposed method, both in the multipliers in the lower limit model are $u_{1}^{*}=0, u_{2}^{*}=0.002235469, v_{1}^{*}=0, v_{2}^{*}=0.03278689$ and in the center model, the multipliers are $u_{1}^{*}=0.005162761, u_{2}^{*}=0.001776794, v_{1}^{*}=0, v_{2}^{*}=0.03278689$, where both cases, the first constraint of model (14) is become as $(0.95082,0.983607,1.04918)$ which apparently satisfied the " $\cong$ " relation. Both examples show that the feasibility of the proposed method is guaranteed. In fact, in both methods the first constraint is transformed to $\sum_{i=1}^{m} v_{i} \tilde{x}_{i 0} \geq 1$ which consequently overestimated the efficiency of DMUs, while this is prevailed in the proposed method.

\section{Conclusions}

In this paper a model is proposed to solve data envelopment analysis models, when the inputs and outputs are determined ambiguously by fuzzy numbers. The method is developed based on the concept of $\alpha$-cuts which transform the fuzzy problem to an equivalent parametric problem. Then, the parametric problem is solved based on different values of $\alpha$. The proposed method is developed either for constant return to scale CCR model and variable return to scale $\mathrm{BCC}$ model. The application of the proposed method is also presented and compared with two existing methods.

One of the advantages of the proposed method is that it can be used for symmetric and asymmetric fuzzy numbers. Also, the proposed method provides frameworks to analysis the efficiency appraisal problems under CCR and BCC models. The major advantage of the proposed model is that its results guaranteed the feasibility of DEA results in original fuzzy model, while other methods don't have such property in some cases. Another feature of the proposed method is that it is a linear programming based parametric method which makes it easy to solve it with the present approaches and applications.

\section{Bibliography}

[1] Banker R.D., Charnes A., Cooper W.W., Some models for estimating technical and scale inefficiencies in data envelopment analysis, MANAGE. SCI. ISSN 0025-1909, 30 (9): 10781092, 1984.

[2] Bellman R.E., Zadeh L.A., Decision making in a fuzzy environment, MANAGE. SCI. ISSN 0025-1909, 17 (4): 141-164, 1970.

[3] Bojadziev G., Bojadziev M.,Fuzzy sets, fuzzy logic, applications, World Scientific Publishing, Singapore, 1996.

[4] Charnes A., Cooper W.W., Programming with linear fractional functions, NAV. RES. LOG. ISSN 0894-069X, 9 (3-4): 181-186, 1962.

[5] Charnes A., Cooper W.W., Rhodes E., Measuring Efficiency of Decision Making Units, EUR. J. OPER. RES. ISSN 0377-2217, 2: 429-444, 1978. 
[6] Chen C.B., Klein C.M., A simple approach to ranking a group of aggregated fuzzy utilities. IEEE. T. SYST. MAN. CY B. ISSN 1083-4419, 27 (1): 26-35, 1997.

[7] Coelli T.J., Prasada Rao D.S., O'Donnell C.J., Battese G.E., An Introduction to Efficiency and Productivity Analysis, 2nd edition, Springer, New York, 2005.

[8] Cook W.D., Seiford L.M., Data envelopment analysis (DEA) "thirty years on. EUR. J. OPER. RES. ISSN 0377-2217, 192 (1): 1-17, 2009.

[9] Cooper W.W., Seiford L.M., Tone K., Data Envelopment Analysis: A Comprehensive Text with Models, Applications, References, and DEA-Solver Software, 2nd ed., Kluwer Academic Publishers, New York, 2006.

[10] Das S.K., Goswami A., Alam S.S., Multiple objective transportation problem with interval cost, source and destination parameters, EUR. J. OPER. RES. ISSN 0377-2217, 117 (1): 100-112, 1999.

[11] Dubois D., Prade H., Operations on fuzzy numbers. INT. J. SYST. SCI. ISSN 0020-7721, 9 (6): 613-626, 1978.

[12] Emrouznejad A., Parker B.R., Tavares G. Evaluation of research in efficiency and productivity: A survey and analysis of the first 30 years of scholarly literature in DEA, SOCIO. ECON. PLAN. SCI. ISSN 0038-121, 42 (3): 151-157, 2008.

[13] Fare R., Zelenyuk V., On Farrell's Decomposition and aggregation. INT. J. BUS. ECON. ISSN 1607-0704, 4 (2): 167-171, 2005.

[14] Guo P. Fuzzy data envelopment analysis and its application to location problems, INFORM. SCIENCES. ISSN 0020-0255, 179 (6): 820-829, 2009.

[15] Hatami-Marbini A., Emrouznejad A., Tavana M., A taxonomy and review of the fuzzy data envelopment analysis literature: two decades in the making, EUR. J. OPER. RES. ISSN 0377-2217, 214 (3): 457-472, 2011.

[16] Hirschey M., Managerial Economics, 12th ed., South Western Cengage Learning, Ohio, 2008.

[17] Ishibuchi H., Tanaka H., Multiobjective programming in optimization of the interval objective function, EUR. J. OPER. RES. ISSN 0377-2217, 48 (2): 219-225, 1990.

[18] Jain R., Decision-Making in the presence of fuzzy variables, IEEE. T. SYST. MAN. CY B. ISSN 1083-4419, 6 (10): 698-703, 1976.

[19] Kao C., Liu S.T., Fuzzy efficiency measures in data envelopment analysis, FUZZY. SET. SYST. ISSN 0165-0114, 113 (3): 427-437, 2000.

[20] Kumbhakar S.C., Knox Lovell C.A., Stochastic Frontier Analysis, Cambridge University Press, Cambridge, 2003.

[21] Lertworasirikul S., Fang S.C., Joines J.A., Nuttle H.L.W., Fuzzy data envelopment analysis (DEA): a possibility approach, FUZZY. SET. SYST., ISSN 0165-0114, 139 (2): 379-394, 2003.

[22] Lertworasirikul S., Fang S.C., Nuttle H.L.W., Joines J.A., Fuzzy BCC model for data envelopment analysis, FUZZY. OPTIM. DECIS. MA. ISSN 1568-4539, 2 (4): 337-358, 2003. 
[23] Luban F., Measuring efficiency of a hierarchical organization with fuzzy DEA method, ECONOMIA. SERIA. MANAGEMENT., ISSN 1454-0320, 12 (1): 87-97, 2009.

[24] Moore R.E., Baker Kearfott R., Cloud M.J., Introduction to interval analysis, SIAM, Philadelphia, 2009.

[25] Ray S.C., Data Envelopment Analysis: Theory and Techniques for Economics and Operations Research, first ed., Cambridge University Press, New York, 2004.

[26] Saati-Mohtadi S., Memariani A., Jahanshahloo G.R., Efficiency analysis and ranking of DMUs with fuzzy data, FUZZY. OPTIM. DECIS. MA., ISSN 1568-4539, 1 (3): 255-267, 2002 .

[27] Sengupta J.K., Data envelopment analysis for efficiency measurement in the stochastic case, COMPUT. OPER. RES. ISSN 0305-0548, 14 (2): 117-129, 1987.

[28] Sengupta J.K., Measuring economic efficiency with stochastic input-output data, INT. J. SYST. SCI., ISSN 0020-7721, 20 (2): 203-213, 1989.

[29] Sengupta J.K., A fuzzy systems approach in data envelopment analysis, COMPUT. MATH. APPL. ISSN 0898-1221, 24 (8-9): 259-266, 1992.

[30] Siler W., Buckley J.J., Fuzzy expert systems and fuzzy reasoning, John Wiley and Sons, New Jersey, 2005.

[31] Wang C.H., Chuang C.C., Tsai C.C., A fuzzy DEA-neural approach to measuring design service performance in PCM projects, AUTOMAT. CONSTR., ISSN 0926-5805, 18 (5): 702-713, 2009.

[32] Zadeh L.A., Fuzzy Sets. INFORMATION AND CONTROL., ISSN 0019-9958, 8 (3): 338353, 1965.

[33] Zerafat Angiz M., Emrouznejad A., Mustafa A., Al-Eraqi A.S., Aggregating preference ranking with fuzzy data envelopment analysis, KNOWL-BASED SYST. ISSN 0950-7051, 23 (6): 512-519, 2010.

[34] Zimmermann H.J., Fuzzy sets theory and its application, forth ed., Kluwer Academic Publishers, Massachusetts, 2001. 